\title{
Subtraction SPECT for Parathyroid Scintigraphy Based on Maximization of Mutual Information
}

Narihiro Hara, $\mathrm{RT}^{1,2}$, Teruhiko Takayama, $\mathrm{MD}^{2}$, Masahisa Onoguchi, $\mathrm{PhD}^{2}$, Norikazu Obane ${ }^{3}$, Toshiaki Miyati, $\mathrm{PhD}^{2}$, Toshiaki Yoshioka, $\mathrm{MD}^{4}$, Katsuhiko Sakaguchi, $\mathrm{MD}^{5}$, and Minoru Honda, $\mathrm{RT}^{1}$

${ }^{I}$ Department of Radiological Technology, Sumitomo Hospital, Nakanoshima, Kita-ku, Osaka, Japan; ${ }^{2}$ Department of Health Sciences, Graduate School of Medical Sciences, Kanazawa University, Kodatsuno, Kanazawa, Japan; ${ }^{3}$ Department of Ultrasonic Examination, Sumitomo Hospital, Nakanoshima, Kita-ku, Osaka, Japan; ${ }^{4}$ Department of Urology, Sumitomo Hospital, Nakanoshima, Kita-ku, Osaka, Japan; and ${ }^{5}$ Department of Internal Medicine, Sumitomo Hospital, Nakanoshima, Kita-ku, Osaka, Japan

Our objective was to investigate the feasibility of subtraction for SPECT images of ${ }^{99 \mathrm{~m} T c-M I B I}$ double-phase parathyroid scintigraphy. Methods: Fourteen patients with hyperparathyroidism were enrolled in the present study. Histopathologically, excised tissue specimens showed hyperplasia in 11 patients and adenoma in 3 patients. Both ultrasonography and $99 \mathrm{mTc}$-sestamibi (MIBI) SPECT images were obtained from all patients. As standard lines to ensure that patient positioning remained identical between the different phases, we used the cross-marker produced by a pair of laser pointers, the orbitomeatal line, and the vertical midline through the patient's nose. Data processing was performed with software that enables image registration by maximization of mutual information. The results of subtraction SPECT imaging were compared with those of ultrasonography. Results: The registration of double-phase SPECT images was successful in all patients when the salivary glands were excluded from the image reconstruction region. The overall sensitivities of scintigraphy and ultrasonography were $90.9 \%$ (40/44) and $70.5 \%$ (31/44), respectively, with respective specificities of $83.3 \%$ (10/12) and $75.0 \%$ (9/12). Scintigraphy and ultrasonography showed accuracies of $92.8 \%(52 / 56)$ and $71.4 \%(40 / 56)$, respectively. Conclusion: The new technique used in the present study allowed the subtraction for SPECT images. The sensitivity of parathyroid lesion detection using this technique was superior to that of ultrasonography.

Key Words: hyperparathyroid; SPECT; subtraction; doublephase imaging; laser pointer

J Nucl Med Technol 2007; 35:84-90

DOI: $10.2967 /$ jnmt.106.033480

\section{$\mathbf{U}$} ltrasonography is the first diagnostic modality for the assessment of parathyroid glands because of its convenience and relatively high degree of sensitivity $(1-4)$. However, the diagnostic accuracy of this modality is markedly affected by the skill of the operator. ${ }^{99 \mathrm{~m} T c-S e s t a m i b i}$

Received Jun. 1, 2006; revision accepted Jan. 2, 2007.

For correspondence or reprints contact: Narihiro Hara, RT, Department of Radiological Technology, Sumitomo Hospital, Nakanoshima, Kita-ku, Osaka, Japan.

E-mail: hara-narihiro@sumitomo-hp.or.jp

COPYRIGHT @ 2007 by the Society of Nuclear Medicine, Inc.
(MIBI) has also been approved as an effective diagnostic imaging agent. Since the introduction of double-phase imaging using this tracer, the technique is currently accepted as the standard examination for patients with hyperparathyroidism because of its acceptable sensitivity and costeffectiveness (5-9). Double-phase imaging is usually used with the subtraction technique. However, the subtraction technique is performed on planar images, not on SPECT images. It has been reported that double-phase MIBI scintigraphy did not have sufficient sensitivity for the detection of parathyroid lesions (10). Because SPECT images can provide information for differentiating between thyroid and parathyroid lesions and for localizing ectopic parathyroid lesions, SPECT was expected to increase the sensitivity and accuracy of the detection of abnormal parathyroid glands (11-13). To our knowledge, there have been no previous reports of the subtraction of SPECT images taken at different phases with a single tracer. We developed a new technique for precise subtraction of cervical SPECT images between different phases using a laser beam and maximization of mutual information.

The purpose of this study was to investigate the feasibility of the subtraction technique for double-phase SPECT images to increase the sensitivity of parathyroid lesion detection.

\section{MATERIALS AND METHODS}

\section{Patient Population}

This study included 14 patients (4 women and 10 men) with hyperparathyroidism, ranging in age from 37 to 74 y (mean age \pm $\mathrm{SD}, 58 \pm 8.5 \mathrm{y})$. Table 1 shows the clinical data. Of 14 patients, $11(79 \%)$ received regular hemodialysis 3 times a week for a mean of 170 mo (range, 84-300 mo). Most (or all) patients showed an increase in serum phosphate (normal, 2.7-4.4 mg/dL), alkaline phosphatase (normal, 115-359 IU/L), and parathyroid hormone (normal, $10-60 \mathrm{pg} / \mathrm{mL}$ ) before surgery, although serum calcium (normal, 8.2-10.2 $\mathrm{mg} / \mathrm{dL}$ ) was within normal limits. Of 44 parathyroid glands, 41 glands were excised and histopathologic examination revealed hyperplasia (Table 2). The remaining 3 glands in 2 patients (patients 3 and 5) were not excised, and no histopathologic examination was performed. Of the total 14 patients, the remaining 3 patients were referred for examination of 
TABLE 1

Summary of Clinical Data

\begin{tabular}{|c|c|c|c|c|c|c|c|c|c|c|c|}
\hline \multirow{3}{*}{$\begin{array}{c}\text { Patient } \\
\text { no. }\end{array}$} & \multirow{3}{*}{$\begin{array}{l}\text { Age } \\
(y)\end{array}$} & \multirow[b]{3}{*}{ Sex } & \multirow[b]{3}{*}{ Dialysis } & \multicolumn{8}{|c|}{ Blood test } \\
\hline & & & & \multicolumn{2}{|c|}{$\begin{array}{c}\text { Calcium }(\mathrm{mg} / \mathrm{dL} \text { ) } \\
\text { (normal, } 8.2-10.2 \\
\mathrm{mg} / \mathrm{dL} \text { ) }\end{array}$} & \multicolumn{2}{|c|}{$\begin{array}{c}\text { Phosphorus } \\
\text { (mg/dL) (normal, } \\
2.7-4.4 \mathrm{mg} / \mathrm{dL} \text { ) }\end{array}$} & \multicolumn{2}{|c|}{$\begin{array}{c}\text { ALP (IU/L) } \\
\text { (normal, 115-359 } \\
\text { IU/L) }\end{array}$} & \multicolumn{2}{|c|}{$\begin{array}{c}\text { Internal secretion, PTH } \\
(\mathrm{pg} / \mathrm{mL})(\text { normal, } \\
10-60 \mathrm{pg} / \mathrm{mL})\end{array}$} \\
\hline & & & & Before & After & Before & After & Before & After & Before & After \\
\hline 1 & 37 & $M$ & + & 8.8 & 7.0 & 7.5 & 3.9 & 483 & 889 & 1015 & 10 \\
\hline 2 & 37 & $M$ & + & 7.1 & 6.4 & 4.6 & 4.3 & 354 & 371 & 274 & 60 \\
\hline 3 & 54 & $M$ & + & 9.7 & 8.4 & 5.8 & 3.0 & 403 & 626 & 762 & 140 \\
\hline 4 & 60 & $\mathrm{~F}$ & + & 9.7 & 8.0 & 4.6 & 3.9 & 298 & 304 & 933 & 136 \\
\hline 5 & 62 & $M$ & + & 8.2 & 7.7 & 4.5 & 3.8 & 443 & 837 & 778 & 12 \\
\hline 6 & 58 & $M$ & + & 9.9 & 9.8 & 7.3 & 3.9 & 363 & 584 & 497 & 7 \\
\hline 7 & 53 & $M$ & + & 10.2 & 7.2 & 8.5 & 6.2 & 175 & 263 & 1,258 & 126 \\
\hline 8 & 63 & $M$ & + & 9.8 & 7.8 & 7.9 & 4.1 & 542 & 748 & 780 & 7 \\
\hline 9 & 52 & $M$ & + & 10.0 & 8.7 & 6.1 & 3.4 & 273 & 311 & 533 & 12 \\
\hline 10 & 61 & $M$ & + & 10.0 & 7.6 & 6.3 & 4.3 & 245 & 248 & 490 & 5 \\
\hline 11 & 59 & $M$ & + & 9.4 & 8.7 & 5.0 & 3.9 & 443 & 439 & 1,236 & 10 \\
\hline 12 & 74 & $\mathrm{~F}$ & - & 10.9 & 9.0 & 3.6 & 3.1 & 233 & 239 & 180 & 74 \\
\hline 13 & 64 & $\mathrm{~F}$ & - & 11.1 & 9.0 & 2.7 & 2.7 & 370 & 327 & 180 & 40 \\
\hline 14 & 56 & $\mathrm{~F}$ & - & 11.4 & 9.7 & 2.9 & 2.5 & 287 & 259 & 62 & 39 \\
\hline
\end{tabular}

ALP = alkaline phosphatase; PTH = parathyroid hormone; before $=$ data within 2 wk before surgery; after $=$ data within 5 d after surgery.

hypercalcemia. In these 3 patients, 3 parathyroid glands were excised and histopathologic examination revealed adenoma. The remaining 9 glands were not excised, and no histopathologic examination was performed. All patients underwent $99 \mathrm{~m}$ Tc-MIBI scintigraphy in addition to cervical ultrasonography, and they then underwent parathyroidectomy within $2 \mathrm{wk}$. As shown in Table 1 , most patients showed a remarkable improvement in serum phosphate and parathyroid hormone levels after surgery. The levels of serum calcium in patients with hyperplasia decreased to less than the normal level after surgery, whereas the serum calcium that was increased before surgery in patients with adenoma was within normal limits after surgery.

\section{Cervical Ultrasonography}

Ultrasonography was performed by a skilled sonographer using a LOGIQ 500 (GE Yokogawa Medical Systems) with a real-time $11-\mathrm{MHz}$ linear B-mode scanner. The patient was placed supine with the neck hyperextended, and then the parathyroid and the thyroid were examined with transverse and sagittal scanning. Table 2 shows the sizes of parathyroid lesions measured in 3 directions. The findings were analyzed with respect to echo texture, homogeneity of the internal structure, configuration, and location (3). When the image delineated a relatively hypoechoic or anechoic homogeneous area with an oval shape and regular borders, the parathyroid lesion was evaluated as positive. The sonographer recorded the site and size of parathyroid lesions, dividing the thyroid region into 4 subregions: upper right, lower right, upper left, and lower left.

\section{Positioning with Laser Beam}

To ensure that patient positioning remained identical between the 2 scan sessions, we used the cross-marker produced by a pair of laser pointers (LTC-L38P; Laser Techno Co., Ltd.) instead of a radionuclide marker, aligning them at right angles (Fig. 1). The device was recently developed for the precise detection of standard lines in the domain of architecture. The body of the equipment contains a gyroscope and is supported by 3 stands. The vertical and horizontal lines of a laser beam are simultaneously emitted from 2 windows and projected to draw a cross-marker on the surface of an object. After the laser pointers were set at suitable positions so that the cross-marker coincided with the central lines of the detector, the cross-markers were traced with a waterresistant pencil on both walls of the laboratory. Accordingly, the intersection of the laser beams emitted at right angles to each other represented the center of rotation of the detectors (point $\mathrm{O}$ in Fig. 1B).

The patient was placed supine on the imaging table and was inserted into the gantry feet first. First, the imaging table was moved right and left in the $x$-axis direction in Figure 1B so that the vertical midline through the patient's nose coincided with the vertical beam line produced by the laser pointer $\mathrm{D}$, represented as the $y$-axis. Next, the imaging table was moved along the $z$-axis. The disposition of the head was adjusted using a pillow made of vesicant styrol so that the orbitomeatal line coincided with the vertical beam line produced by the laser pointer C. It was inevitable that the external auditory canal would be strictly coincident with the center of rotation of the detectors in the course of the laser beam. The patient left the imaging table after completion of the early imaging acquisition.

Before the delayed imaging acquisition, the locations of the laser pointers were reconfirmed with the cross-markers drawn on the walls. Then, adjustment of the patient's position was repeated using the laser beam. Thus, the patient's position on the imaging table was kept identical between the different phases.

\section{Data Acquisition}

Imaging was performed with a dual-detector $\gamma$-camera system (FORTE; ADAC Laboratories) equipped with a Vertex generalpurpose parallel collimator, developed by the manufacturer for exclusive use with SPECT. Double-phase ${ }^{99 \mathrm{~m} T c-M I B I}$ scintigraphy was performed according to the following protocol. The early 
TABLE 2

Results of Scintigraphy, Ultrasonography, and Surgery

\begin{tabular}{|c|c|c|c|c|c|c|}
\hline \multirow[b]{2}{*}{ Patient no. } & \multicolumn{2}{|c|}{ Scintigraphy } & \multicolumn{2}{|c|}{ Ultrasonography } & \multicolumn{2}{|c|}{ Surgery/pathology } \\
\hline & Location & $+1-$ & Size $(\mathrm{mm})$ & $+1-$ & Histopathology & Weight (mg) \\
\hline \multirow[t]{4}{*}{1} & $\mathrm{RU}$ & + & & - & Parathyroid hyperplasia & 350 \\
\hline & $\mathrm{RL}$ & + & $16 \times 15 \times 15$ & + & Parathyroid hyperplasia & 1,650 \\
\hline & LU & + & & - & Parathyroid hyperplasia & 800 \\
\hline & LL & + & $18 \times 13 \times 11$ & + & Parathyroid hyperplasia & 1,100 \\
\hline \multirow[t]{4}{*}{2} & RU & + & & - & Parathyroid hyperplasia & 1,600 \\
\hline & $\mathrm{RL}$ & + & $23 \times 10 \times 9$ & + & Parathyroid hyperplasia & 200 \\
\hline & LU & + & & - & Parathyroid hyperplasia & 1,300 \\
\hline & LL & + & $6 \times 5 \times 5$ & + & Parathyroid hyperplasia & 300 \\
\hline \multirow[t]{4}{*}{3} & $\mathrm{RU}$ & + & $21 \times 14 \times 9$ & + & Parathyroid hyperplasia & 1,600 \\
\hline & $\mathrm{RL}$ & + & $13 \times 11 \times 10$ & + & Parathyroid hyperplasia & 500 \\
\hline & LU & + & & - & No excision & \\
\hline & LL & - & $12 \times 10 \times 6$ & + & Parathyroid hyperplasia & 300 \\
\hline \multirow[t]{4}{*}{4} & $\mathrm{RU}$ & + & & - & Parathyroid hyperplasia & 500 \\
\hline & $\mathrm{RL}$ & + & $10 \times 6 \times 5$ & + & Parathyroid hyperplasia & 250 \\
\hline & LU & + & & - & Parathyroid hyperplasia & 450 \\
\hline & LL & + & $8 \times 8 \times 7$ & + & Parathyroid hyperplasia & 400 \\
\hline \multirow[t]{4}{*}{5} & RU & - & & - & No excision & \\
\hline & $\mathrm{RL}$ & - & $10 \times 6 \times 5$ & + & No excision & \\
\hline & LU & + & & - & Parathyroid hyperplasia & 1,600 \\
\hline & LL & + & $16 \times 12 \times 10$ & + & Parathyroid hyperplasia & 400 \\
\hline \multirow[t]{4}{*}{6} & $\mathrm{RU}$ & + & & - & Parathyroid hyperplasia & 1,450 \\
\hline & $\mathrm{RL}$ & + & $11 \times 10 \times 8$ & + & Parathyroid hyperplasia & 600 \\
\hline & LU & + & & - & Parathyroid hyperplasia & 2,250 \\
\hline & LL & + & $10 \times 8 \times 7$ & + & Parathyroid hyperplasia & 700 \\
\hline \multirow[t]{4}{*}{7} & RU & + & $6 \times 6 \times 3$ & + & Parathyroid hyperplasia & 950 \\
\hline & $\mathrm{RL}$ & + & $11 \times 4 \times 3$ & + & Parathyroid hyperplasia & 350 \\
\hline & LU & + & & - & Parathyroid hyperplasia & 2,050 \\
\hline & $\mathrm{LL}$ & + & $12 \times 11 \times 3$ & + & Parathyroid hyperplasia & 350 \\
\hline \multirow[t]{4}{*}{8} & $\mathrm{RU}$ & + & $9 \times 8 \times 8$ & + & Parathyroid hyperplasia & 1,950 \\
\hline & $\mathrm{RL}$ & + & $20 \times 11 \times 14$ & + & Parathyroid hyperplasia & 300 \\
\hline & LU & + & $11 \times 7 \times 7$ & + & Parathyroid hyperplasia & 250 \\
\hline & LL & + & $11 \times 11 \times 6$ & + & Parathyroid hyperplasia & 400 \\
\hline \multirow[t]{4}{*}{9} & $\mathrm{RU}$ & + & & - & Parathyroid hyperplasia & 1,500 \\
\hline & $\mathrm{RL}$ & - & $23 \times 13 \times 8$ & + & Parathyroid hyperplasia & 900 \\
\hline & LU & - & & - & Parathyroid hyperplasia & 600 \\
\hline & LL & - & & - & Parathyroid hyperplasia & 200 \\
\hline \multirow[t]{4}{*}{10} & $\mathrm{RU}$ & + & $10 \times 8 \times 5$ & + & Parathyroid hyperplasia & 400 \\
\hline & $\mathrm{RL}$ & + & $12 \times 9 \times 7$ & + & Parathyroid hyperplasia & 700 \\
\hline & LU & + & $6 \times 6 \times 8$ & + & Parathyroid hyperplasia & 300 \\
\hline & $\mathrm{LL}$ & + & $10 \times 10 \times 4$ & + & Parathyroid hyperplasia & 500 \\
\hline \multirow[t]{4}{*}{11} & $\mathrm{RU}$ & + & $8 \times 7 \times 5$ & + & Parathyroid hyperplasia & 100 \\
\hline & $\mathrm{RL}$ & + & $13 \times 9 \times 7$ & + & Parathyroid hyperplasia & 200 \\
\hline & LU & + & $6 \times 5 \times 4$ & + & Parathyroid hyperplasia & 50 \\
\hline & $\mathrm{LL}$ & + & $17 \times 13 \times 6$ & + & Parathyroid hyperplasia & 500 \\
\hline \multirow[t]{4}{*}{12} & $R U$ & - & & - & No excision & \\
\hline & $\mathrm{RL}$ & - & & - & No excision & \\
\hline & LU & + & $15 \times 5 \times 3$ & + & Adenoma & 300 \\
\hline & LL & + & $16 \times 5 \times 3$ & + & No excision & \\
\hline \multirow[t]{4}{*}{13} & $\mathrm{RU}$ & + & $20 \times 7 \times 4$ & + & Adenoma & 500 \\
\hline & $\mathrm{RL}$ & - & & - & No excision & \\
\hline & LU & - & & - & No excision & \\
\hline & LL & - & $8 \times 8 \times 4$ & + & No excision & \\
\hline 14 & $\mathrm{RU}$ & - & & - & No excision & \\
\hline & $\mathrm{RL}$ & + & $6 \times 4 \times 4$ & + & Adenoma & 300 \\
\hline & LU & - & & - & No excision & \\
\hline & $\mathrm{LL}$ & - & & - & No excision & \\
\hline
\end{tabular}




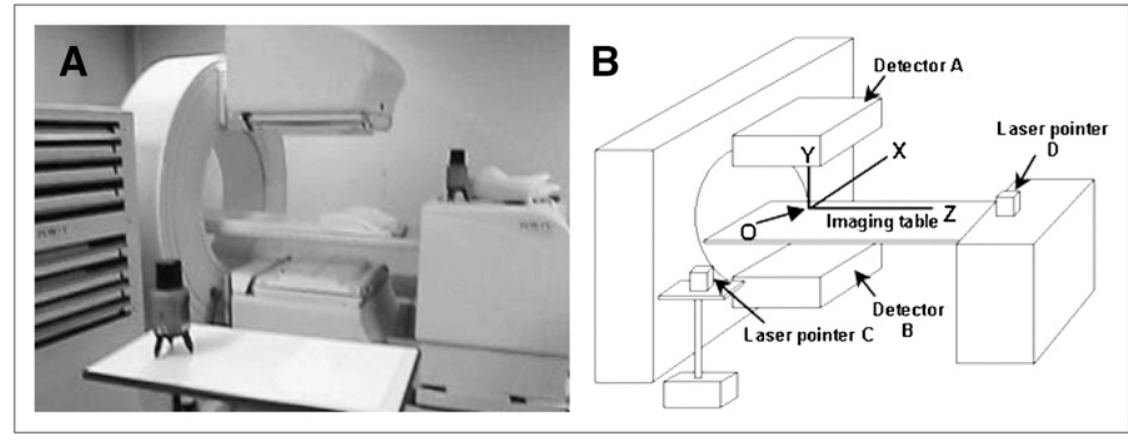

FIGURE 1. Appearance (A) and illustration (B) of pair of laser pointers aligned at right angles. Point $\mathrm{O}$ corresponds to center of rotation of detectors. planar image (anterior view) was acquired 15 min after intravenous injection of $600 \mathrm{MBq}$ of ${ }^{99 \mathrm{~m}} \mathrm{Tc}-\mathrm{MIBI}$ and was followed immediately by early SPECT. Then, the delayed planar image was acquired $120 \mathrm{~min}$ after the injection, followed by delayed SPECT. Acquisition times were 1,200 and 1,511 s for the early and delayed planar images, respectively, using a $512 \times 512$ matrix with a zoom factor of $2.19(1 \mathrm{pixel}=0.53 \mathrm{~mm})$. Using the elliptic orbit (semimajor axis length, $\sim 26 \mathrm{~cm}$; semiminor axis length, $\sim 20$ $\mathrm{cm})$, the SPECT data were acquired at $20 \mathrm{~s} / \mathrm{step}$ and $25 \mathrm{~s} / \mathrm{step}$ for the early and delayed images, respectively, using a $128 \times 128$ matrix with a zoom factor of $1.46(1$ pixel $=3.28 \mathrm{~mm})$.

\section{Data Processing}

The data were reconstructed using filtered backprojection with a Butterworth windowed ramp filter (cutoff, 0.38 cycles $/ \mathrm{cm}$; order, 18). The reconstructed transaxial images were then restored to form the coronal and sagittal images. The reconstructed regions for the early SPECT images included the whole thyroid and the extrathyroid region beneath the thyroid, with one third of the thyroid length on the early planar images. For example, the region for a patient was between lines 13 and 36 (Fig. 2). The distance between both lines was approximately $7.9 \mathrm{~cm}(3.28 \mathrm{~mm} \times 24$ slices). The reconstructed regions for the delayed SPECT images were decided using the same lines as on the early planar images. The reconstructed SPECT data were sent online as Digital Imaging and Communications in Medicine data to a personal computer (CF-Y2CW4AXR; Panasonic) using e-film software (version 2.0; iNfocom). For data processing on the personal computer, free interface software was used to produce the fusion images and then subtraction images (Interface of NEUROSTAT and Neuroimaging Registration Tool, iNRT; Japan Medi-Physics Corp.). For differentiation between the superior and inferior parathyroid glands, the coronal images after registration were produced by applying the iNRT software against the early and delayed coronal SPECT images. Then, the region of the parathyroid gland was determined using the registered coronal images.

\section{Visual Image Interpretation}

The planar images were interpreted by 2 nuclear medicine physicians using the images on display, and interpretation of the SPECT images followed. After the fusion SPECT images had confirmed the success of the coregistration, the subtraction SPECT images were interpreted. Similar to ultrasonography, the location of the lesion was recorded, dividing the total regions explored into 4 subregions. The superior and inferior parathyroid glands were discriminated on the basis of a line one third the length of the thyroid from the bottom of the thyroid. That is, retained radiotracer in the slices over and under the line was considered to represent the superior and inferior parathyroid lesions, respectively. When retention of radiotracer on the subtraction SPECT images appeared as a solitary focus, it was interpreted as an adenoma; 2 or more foci of persistent radiotracer activity were interpreted as hyperplasia; no radiotracer retention was regarded as a normal finding.

\section{Reproducibility of Technique}

Before the clinical study, we studied the reproducibility of the technique using an acryl phantom and a point source $(0.5 \mathrm{~mm}$ in diameter). The evaluation was performed by comparing the distance between the point source and the basal line on the reconstructed transversal SPECT image. The basal line on images was found from the center of the matrix. The point source in the acryl phantom was placed to coincide with the center of rotation of the detectors found by the laser beam method and visually. Scans were repeated 10 times. With the laser beam method, the distances (mean $\pm \mathrm{SD}$ ) between the point source and the basal line were
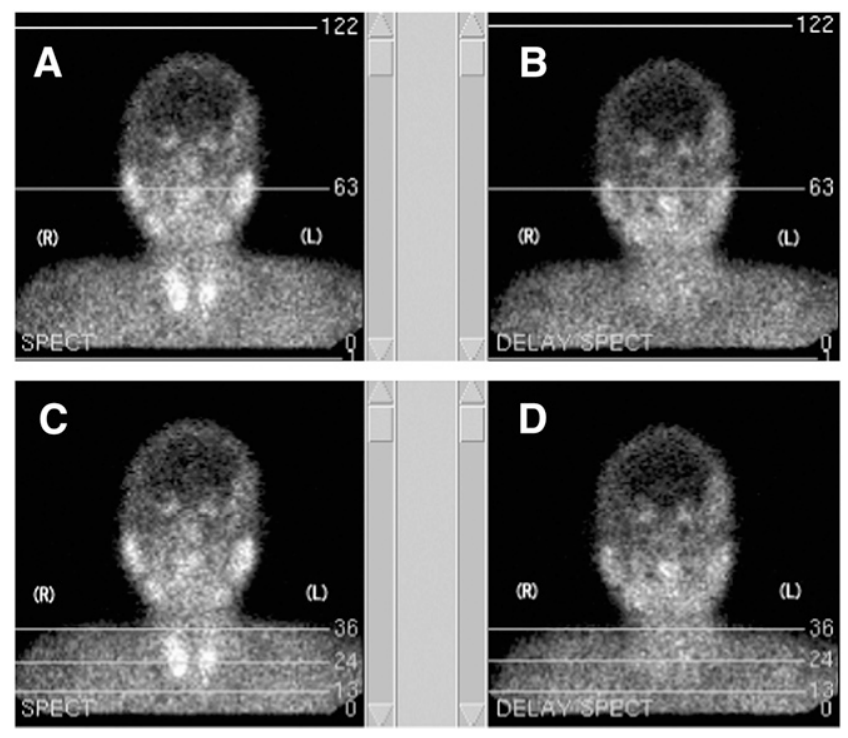

FIGURE 2. Planar images used to select reconstructed regions for SPECT images. (A and C) Early planar images. Line marked 63 in $A$ is centerline in 128 matrix. Centerline passes through right and left external auditory canals. Region between lines 13 and 36 is reconstructed region on SPECT images, excluding salivary glands. ( $B$ and $D)$ Delayed planar images. Similarly, centerline passes through both external auditory canals. Reconstructed region for delayed SPECT image is similarly selected between lines 13 and 36 . 
$1.9 \pm 1.0 \mathrm{~mm}$ and $0.9 \pm 0.7 \mathrm{~mm}$, respectively, in the semimajor and semiminor axis directions of the elliptic orbit, whereas those values were $4.0 \pm 2.4 \mathrm{~mm}$ and $3.7 \pm 2.8 \mathrm{~mm}$, respectively, on visual observation. Therefore, it was demonstrated that the laser beam method of positioning had excellent reproducibility because of the small SD.

\section{RESULTS}

In our preliminary study, we noticed that the source of misregistration was the presence of high levels of radioactivity. Because the salivary glands were excluded from the reconstructed regions, the images between the different phases were successfully registered for all patients (Fig. 3). Ultrasonography revealed that no patients in this series had thyroid nodules. Surgical results revealed abnormal tissues in the 44 parathyroid glands, consisting of 41 cases of hyperplasia and 3 adenomas. Three glands in 2 patients with hyperplasia and 9 glands in 3 patients with adenoma were not excised. Forty of the 44 lesions in 11 patients with hyperplasia were identified precisely on scintigraphy, compared with 31 lesions on ultrasonography (Table 3). On the other hand, 3 patients with adenoma were identified precisely on both scintigraphy and ultrasonography. Thus, the $90.9 \%$ overall sensitivity (40/44) for scintigraphy was superior to the $70.5 \%$ overall sensitivity (31/44) for ultrasonography. Seven patients showed positive scintigraphy results and negative ultrasonography results, and all had lesions located in the upper regions, indicating the superior parathyroid gland. In contrast, 2 patients (patients 3 and 9) showed positive results on ultrasonography and negative results on scintigraphy and had only 2 lesions located in the lower region. Two glands with hyperplasia (patient 9) were negative on both scintigraphy and ultrasonography. Three glands in 2 patients (patients 3 and 5) with hyperplasia and the remaining 9 glands in 3 patients with adenoma were not excised. Of these 12 glands, 2 and 3 glands were diagnosed as positive on scintigraphy and ultrasonography, respectively. Although not proven by histopathologic examina- tion, the tissue of these 12 glands seemed to be nearly normal. Therefore, the specificities were $91.7 \%$ (11/12) and $83.3 \%(10 / 12)$ on scintigraphy and ultrasonography, respectively. The false-positive and false-negative rates of the scintigraphic results were $16.7 \%(2 / 12)$ and $4.5 \%(2 / 44)$, respectively, compared with $25.0 \%$ (3/12) and $29.5 \%$ (13/44), respectively, for the ultrasonographic results. Consequently, scintigraphy and ultrasonography showed accuracies of $92.8 \%$ (52/56) and 71.4\% (40/56), respectively.

Figures 4 and 5 show images of patients with hyperplasia (patient 10) and adenoma (patient 12), respectively. The subtraction SPECT images clearly revealed the lesions in both cases, whereas the planar images did not show the lesions.

\section{DISCUSSION}

It is well known that the inferior parathyroid glands vary more in location than do the superior parathyroid glands. Because the inferior parathyroid glands arise from the third branchial cleft pouch and migrate caudally, they are more frequently ectopic than are their superior counterparts (1). Parathyroid scintigraphy is more effective than ultrasonography for the detection of ectopic parathyroid glands because scintigraphy can explore them over a wide range. Gayed et al. (8) reported that fused SPECT/CT has no significant clinical value over conventional SPECT for parathyroid imaging except in locating ectopic parathyroid glands. In the present study, we developed a subtraction technique for double-phase SPECT images based on maximization of mutual information. To avoid misregistration, it is essential to use images acquired under identical conditions, especially with the patient in the same position. However, it is difficult to coregister images of the neck region because of a lack of markers. To solve this problem, we used a pair of laser pointers instead of a radionuclide marker. Furthermore, we used the cross-marker produced by a laser beam recorded on the walls, in combination with the orbitomeatal line and the vertical midline through the patient's nose.

FIGURE 3. SPECT images of a patient: early $(A)$, delayed $(B)$, fusion $(C)$, and subtraction (D).
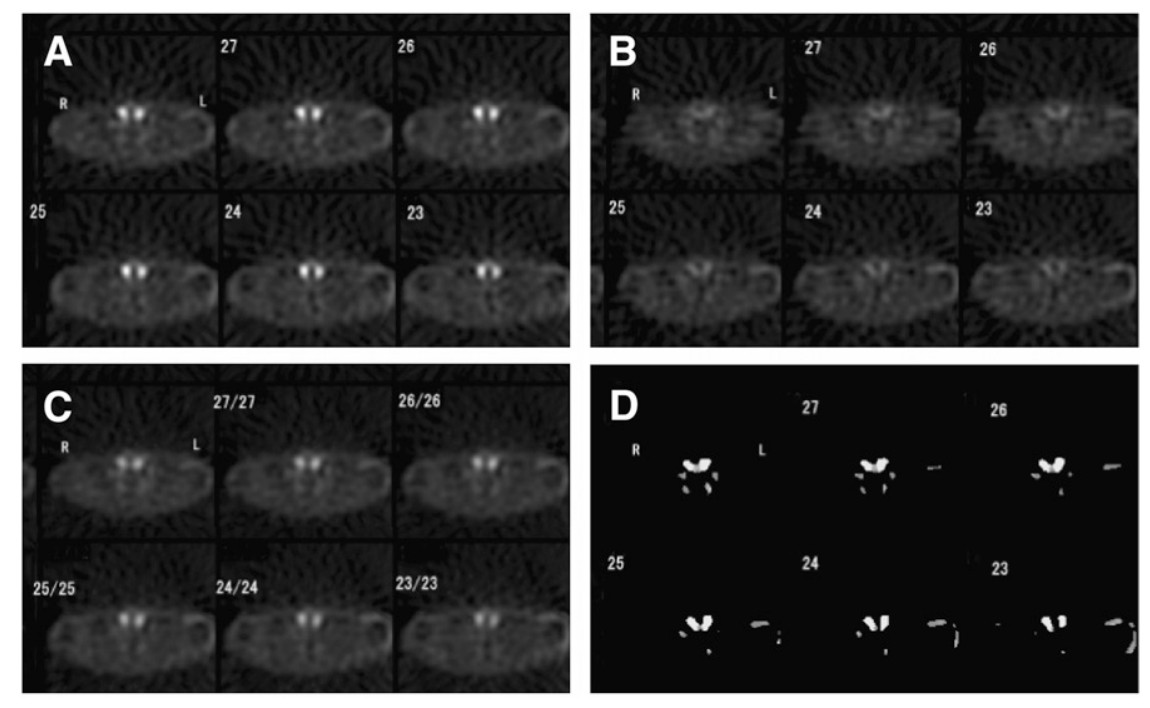
TABLE 3

Comparison of Lesion Detection Between Scintigraphy and Ultrasonography

\begin{tabular}{|c|c|c|c|c|c|c|c|c|c|}
\hline \multirow[b]{2}{*}{ Scintigraphy(+/-) } & \multirow[b]{2}{*}{ Location } & \multicolumn{4}{|c|}{ Ultrasonography $(+)(n=31)$} & \multicolumn{4}{|c|}{ Ultrasonography(-) $(n=13)$} \\
\hline & & $\mathrm{RU}$ & $\mathrm{RL}$ & LU & LL & $\mathrm{RU}$ & $\mathrm{RL}$ & LU & LL \\
\hline \multirow[t]{4}{*}{$+(n=40)$} & $R U$ & 6 & & & & 5 & & & \\
\hline & $\mathrm{RL}$ & & 10 & & & & & & \\
\hline & LU & & & 4 & & & & 6 & \\
\hline & LL & & & & 9 & & & & \\
\hline \multirow[t]{4}{*}{$-(n=4)$} & $\mathrm{RU}$ & & & & & & & & \\
\hline & $\mathrm{RL}$ & & 1 & & & & & & \\
\hline & LU & & & & & & & 1 & \\
\hline & LL & & & & 1 & & & & 1 \\
\hline
\end{tabular}

This trial was valid in determining patient positioning. For production of the subtraction images, we used the iNRT software. This software was developed for registration in the analysis of brain blood flow and allows coregistration between and within modalities by maximizing mutual information. Because the iNRT software processes the data on the basis of the highest levels of radioactivity, inclusion
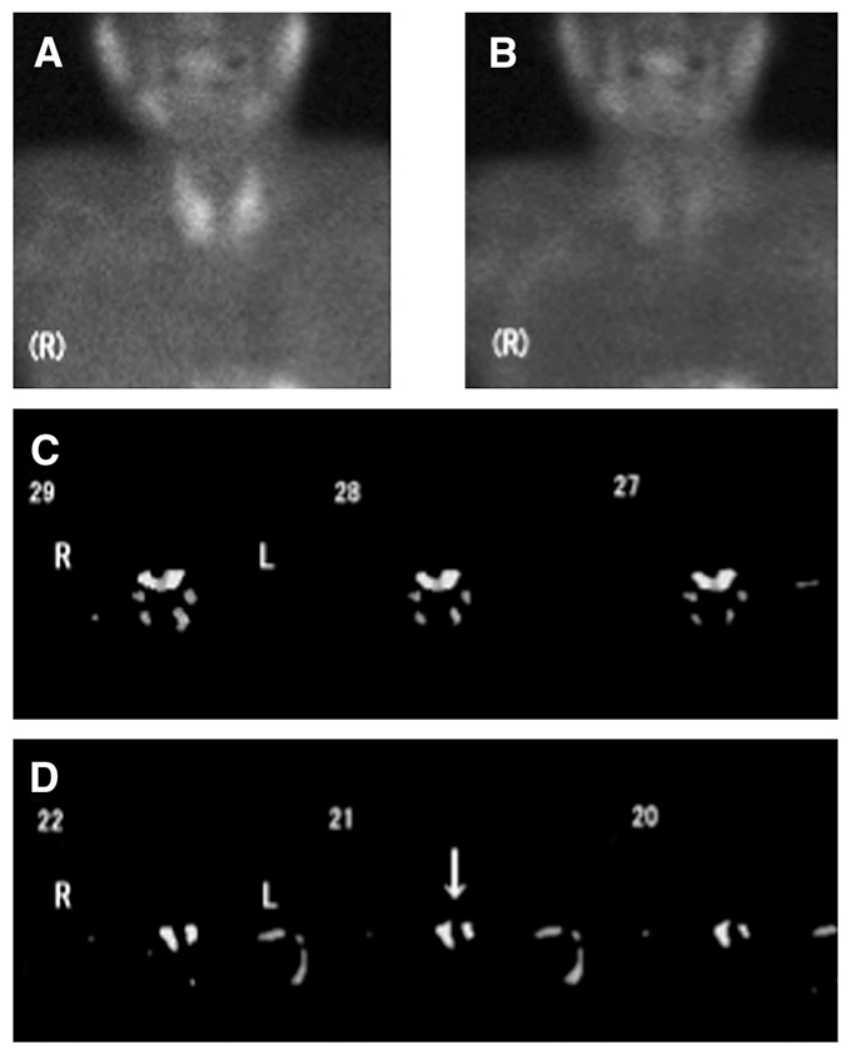

FIGURE 4. A 61-y-old man with 4 hyperplastic glands (patient 10). Glands weighed $300-700 \mathrm{mg}$. In this patient, 24 slices (124) were reconstructed. Slice numbers more and less than 24 were considered to represent superior and inferior parathyroid glands, respectively. (A-D) Early planar image $(A)$, delayed planar image $(B)$, and subtraction SPECT images showing upper (C) and lower (D) parathyroid hyperplasia. Arrow indicates hyperplastic lesion. of the salivary gland within the image reconstruction region causes a mismatch in image fusion, thereby causing image subtraction to fail. Therefore, we concluded that exclusion of the salivary glands from the reconstructed regions would facilitate successful analysis.

Parathyroid scintigraphy, either alone or in combination with ultrasonography, is commonly used for the detection of lesions. Procedure guidelines for parathyroid scintigraphy have been published (5). Localization of ${ }^{99 \mathrm{~m}} \mathrm{Tc}-\mathrm{MIBI}$ in tissue depends not only on the size of the gland but also on blood flow to the tissue, the concentration of $99 \mathrm{~m}$ Tc-MIBI presented to the tissue, and the binding mechanisms in various tissues (14). In particular, the accuracy with which ultrasonography and scintigraphy localize parathyroid lesions varies with the size and location of the lesions (2). Many authors have reported that the sensitivity of ultrasonography in identifying parathyroid lesions ranges from $70 \%$ to $80 \%(1,15)$. However, most of these results were based on the detection of adenoma. Because hyperplastic glands are
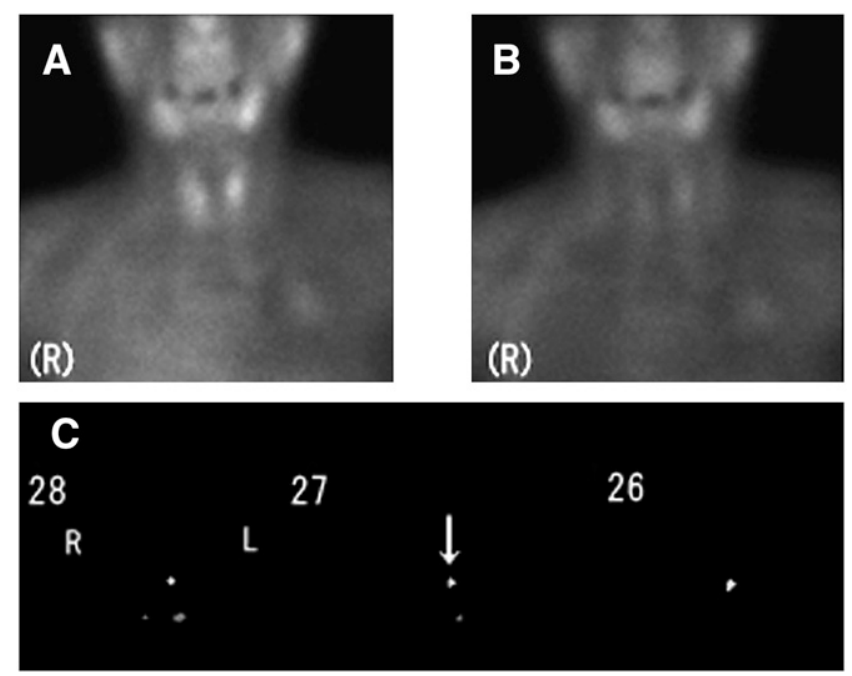

FIGURE 5. A 74-y-old woman with adenoma (patient 12). Lesion weighed $300 \mathrm{mg}$. (A-C) Early planar image (A), delayed planar image (B), and subtraction SPECT images (C). Lesion (arrow) was seen in left upper region. 
usually smaller than adenomas, ${ }^{99 \mathrm{~m}} \mathrm{Tc}-\mathrm{MIBI}$ scintigraphy is less useful in patients with secondary hyperparathyroidism in which the predominant lesion is hyperplasia (1). Ishibashi et al. (16) reported that MIBI double-phase planar imaging of 11 patients had a sensitivity of $78 \%$ and specificity of $75 \%$ in 37 glands with hyperplasia. In contrast, our results showed a higher sensitivity, $90.9 \%$ (40/44).

A difficulty in identifying parathyroid lesions using planar images is that they are posterior to the thyroid gland. For this reason, SPECT is a promising means to increase the sensitivity of detection. Slater et al. (17) reported that SPECT showed a higher sensitivity for lesion detection $(73 \%)$ than did planar imaging (62\%). Gayed et al. (8) reported that SPECT alone identified the parathyroid lesions in $89 \%$ of patients. Lorberboym et al. (18) reported that early SPECT was superior to delayed double-phase imaging.

Tumor size has a marked effect on the results of parathyroid scintigraphy. For small parathyroid tumors $(\leq 250$ $\mathrm{mg}$ ), no imaging technique has had a sensitivity of more than $50 \%$. The weight and size of the parathyroid tumors in our study ranged from 50 to $2,250 \mathrm{mg}$ and from 6 to $23 \mathrm{~mm}$, respectively. It is the resolution of the $\gamma$-camera that limits the detection rates of parathyroid tumors with scintigraphy. The system resolution of our camera was $7.8 \mathrm{~mm}$ (nominal value) in full width at half maximum. Generally, the subtraction technique has certain limitations because patient motion during data acquisition can lead to misregistration of the images, thereby producing a false-positive result (1). On the other hand, Lorberboym et al. (18) reported that gland size did not significantly affect detectability by SPECT because there was no correlation between gland size and parathyroid uptake. O'Doherty et al. (14) reported that the uptake of ${ }^{99 \mathrm{~m} T c-M I B I}$ per gram of tissue was higher for the parathyroid than for the thyroid. Because lower-pole tumors are frequently located beneath the thyroid gland, whereas upperpole tumors usually lie behind the thyroid gland, sensitivity has been reported to be markedly higher for lower-pole adenomas (l). Recent investigations have indicated that, at least in secondary hyperparathyroidism, ${ }^{99 \mathrm{~m} T c-M I B I}$ uptake is more closely related to cell cycle than to gland size (1). Sandrock et al. (19) did not observe any correlations between the detection rate and age, sex, adenoma versus hyperplasia, anatomic localization (upper/lower pole, left/ right), serum parathyroid hormone levels, or prior surgery.

\section{CONCLUSION}

Successful registration of SPECT images was achieved when the salivary glands were excluded from the image reconstruction region in hyperparathyroid patients. The sensitivity of this technique in the detection of parathyroid lesions was superior to that of ultrasonography.

\section{ACKNOWLEDGMENTS}

We thank Osamu Houjou and all the radiologic technologists of Sumitomo Hospital for technical support; Masahiro Takayama and Kazuo Hamada of Nihon Medi-Physics Co., Ltd.; and Jun Ueda, MD, a radiologist, for advice.

\section{REFERENCES}

1. Palestro CJ, Tomas MB, Tronco GG. Radionuclide imaging of the parathyroid glands. Semin Nucl Med. 2005;35:266-276.

2. Mariani G, Gulec SA, Rubello D, et al. Preoperative localization and radioguided parathyroid surgery. $J$ Nucl Med. 2003;44:1443-1458.

3. Kebapci M, Entok E, Kebapci N, Adapinar B. Preoperative evaluation of parathyroid lesions in patients with concomitant thyroid disease: role of high resolution US and dual phase technetium-99m-sestamibi scintigraphy. $J$ Endocrinol Invest. 2004;27:24-30.

4. De Feo ML, Colagrande S, Biagini C, et al. Parathyroid glands: combination of Tc-99m-MIBI scintigraphy and US for demonstration of parathyroid glands and nodules. Radiology. 2000;214:393-402.

5. Greenspan BS, Brown ML, Dillehay GL, et al. Procedure guideline for parathyroid scintigraphy. J Nucl Med. 1998;39:1111-1114.

6. Taillefer R, Boucher Y, Potvin C, Lambert R. Detection and localization of parathyroid adenomas in patients with hyperparathyroidism using a single radionuclide imaging procedure with technetium-99m-sestamibi (double-phase study). J Nucl Med. 1992;33:1801-1807.

7. Gordon L, Burkhalter W, Mah E. Dual-phase ${ }^{99 \mathrm{~m}} \mathrm{Tc}$-sestamibi imaging: its utility in parathyroid hyperplasia and use of immediate/delayed image ratios to improve diagnosis of hyperparathyroidism. J Nucl Med Technol. 2002;30:179-184.

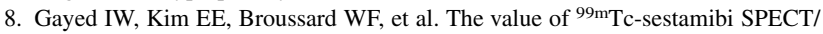
CT over conventional SPECT in the evaluation of parathyroid adenomas or hyperplasia. J Nucl Med. 2005;46:248-252.

9. Demirkurek $\mathrm{CH}$, Adalet I, Terzioglu T, et al. Efficiency of gamma probe and dual-phase Tc-99m sestamibi scintigraphy in surgery for patients with primary hyperparathyroidism. Clin Nucl Med. 2003;28:186-191.

10. Leslie WD, Dupont JO, Bybel B, Riese KT. Parathyroid ${ }^{99 m} \mathrm{Tc}$-sestamibi scintigraphy: dual-tracer subtraction is superior to double-phase washout. Eur J Nucl Med Mol Imaging. 2002;29:1566-1570.

11. Chen CC, Holder LE, Scovill WA, Tehan AM, Gann DS. Comparison of parathyroid imaging with Tc-99m-pertechnetate/sestamibi subtraction, doublephase Tc-99m-sestamibi and Tc-99m-sestamibi SPECT. J Nucl Med. 1997;38: 834-839.

12. Spanu A, Falchi A, Manca A, et al. The usefulness of neck pinhole SPECT as a complementary tool to planar scintigraphy in primary and secondary hyperparathyroidism. J Nucl Med. 2004;45:40-48.

13. Billotey C, Sarfati E, Aurengo A, et al. Advantages of SPECT in technetium99m-sestamibi parathyroid scintigraphy. J Nucl Med. 1996;37:1773-1778.

14. O'Doherty MJ, Kettle AG, Wells P, Collins RE, Coakley AJ. Parathyroid imaging with technetium-99m-sestamibi: preoperative localization and tissue uptake studies. J Nucl Med. 1992;33:313-318.

15. Piga M, Bolasco P, Satta L, et al. Double phase parathyroid technetium-99mMIBI scintigraphy to identify functional autonomy in secondary hyperparathyroidism. J Nucl Med. 1996;37:565-569.

16. Ishibashi M, Nishida H, Hiromatsu Y, Kojima K, Tabuchi E, Hayabuchi N. Comparison of technetium-99m-MIBI, technetium-99m-tetrofosmin, ultrasound and MRI for localization of abnormal parathyroid glands. J Nucl Med. 1998;39: 320-324.

17. Slater A, Gleeson FV. Increased sensitivity and confidence of SPECT over planar imaging in dual-phase sestamibi for parathyroid adenoma detection. Clin Nucl Med. 2005;30:1-3.

18. Lorberboym M, Minski I, Macadziob S, Nikolov G, Schachter P. Incremental diagnostic value of preoperative ${ }^{99} \mathrm{~m}$ Tc-MIBI SPECT in patients with a parathyroid adenoma. J Nucl Med. 2003;44:904-908.

19. Sandrock D, Merino M, Norton JA, Neumann RD. Ultrastructural histology correlates with results of thallium-201/technetium-99m parathyroid subtraction scintigraphy. J Nucl Med. 1993;34:24-29. 